\title{
Neural Circuits for Motion Vision in the Fly
}

\author{
Alexander Borst \\ Max-Planck-Institute of Neurobiology, 82152 Martinsried, Germany \\ Correspondence: borst@neuro.mpg.de
}

\begin{abstract}
Seeing the direction of motion is fundamental for visual navigation, predator avoidance, and prey capture. However, the direction of motion is not explicitly represented at the level of individual photoreceptors. Rather, directional motion information needs to be extracted from the photoreceptor array by comparing the signals of neighboring photoreceptors over time. The exact nature of this process as implemented in the Drosophila visual system is currently being studied in great detail, and much progress has recently been made in determining the neural circuits giving rise to directional motion information in this species.
\end{abstract}

\section{THE CENTRAL PHENOMENON}

Image motion can have two different causes: when the observer is standing still and something else is moving in the environment, or when the observer itself is moving. In the first case, image motion may indicate the presence of a predator, a prey, or a conspecific; in the second case, image motion is indicative for the exact way the observer is moving, whether it is rotating around or translating along a particular body axis. Also, during self-motion, nearby objects will move relative to the background. Thus, image motion can also be used for segmenting the visual scenery. In any case, motion information is of prime importance for the appropriate action the animal should take and therefore is indispensable for survival. However, the direction in which something is moving is not explicitly encoded at the level of single photoreceptors. As depicted in Figure 1, if a bright bar is moved from left to right and back again in front of a fly's eye, the electrical response of a single photoreceptor looks the same. Thus, from the responses of an individual photoreceptor, one cannot tell the direction of local image motion. The fly's optic lobe consists of four different neuropiles called lamina, medulla, lobula, and lobula plate. All these neuropiles are built from repetitive columns, arranged in a retinotopic way. In the lobula plate, large so-called "lobula plate tangential cells" cover many hundreds of different columns with their dendrites. If the response from one of these neurons is recorded during the same stimulation protocol as described previously, a very different behavior is found: During bar motion to the right (their "preferred direction"), the cells depolarize; during bar motion to the left (their "null direction"), they hyperpolarize. In contrast to the photoreceptor signal, these cells apparently encode the direction of image motion in their membrane potential. Obviously, somewhere between the photoreceptor terminals and the dendrites of the lobula plate tangential cells, the direction of motion has been computed. This process is called "elementary motion detection" and is the central topic of interest.

\section{THE HASSENSTEIN-REICHARDT DETECTOR}

Analyzing the turning tendency of the beetle Chlorophanus viridis walking on a spherical Y-maze, Hassenstein and Reichardt (1956) proposed a specific model of elementary motion detection that could account for their observations in a quantitative way. The idea was that the beetle's nervous system contains many hundreds of such elementary units that, collectively, cover the whole visual field, each extracting locally the direction of image motion. The algorithmic model for such an elementary motion detector consists of two subunits, which are mirrorsymmetrical to each other (Fig. 2; Hassenstein and Reichardt 1956; Reichardt 1961, 1987; Borst and Egelhaaf 1989). Each subunit reads the luminance values measured in two adjacent facets. These values pass an input filter before they are fed through temporal filters with different characteristics (low-pass filter, high-pass filter). Next, they are multiplied (M). The output values of both subunits are finally subtracted to result in a directionally selective signal. This model is referred to in the literature as Hassenstein-Reichardt detector, correlation detector, or Reichardt detector. The model makes predictions which are both quantitative and counterintuitive. These predictions have been tested and confirmed in many studies using either the optomotor turning response or the electrical signals of the lobula plate tangential cells as a readout (for the blow fly Calliphora, see, e.g., Egelhaaf and Borst 1989; Brenner et al. 2000; Borst et al. 2003, 2005; Reisenman et al. 2003; Haag et al. 2004; for the house fly Musca, see, e.g., Fermi and Reichardt 1963; Eckert 1973; Borst and Bahde 1986; for the fruit fly Drosophila, see, e.g., Goetz 1964, 1965; Buchner 1976; Joesch et al. 2008; Schnell et al. 2010). 


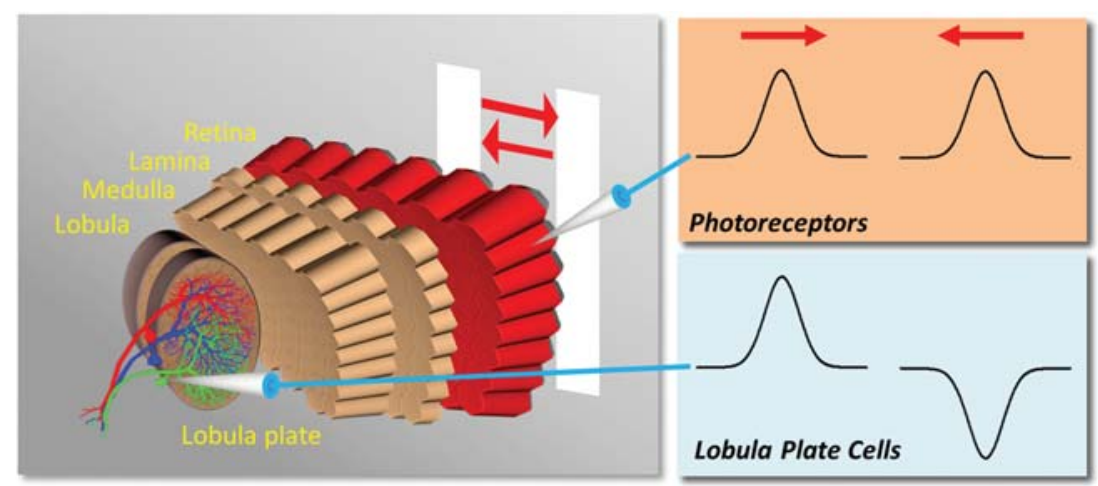

Figure 1. From nondirectional to directional responses. (Left) Schematic of the optic lobe of Drosophila. The retina (red) built from repetitive facets is followed by four layers of neuropile, called lamina, medulla, lobula, and lobula plate. Within the lobula plate, the group of three horizontal system (HS) cells is shown as reconstructed from stained tissue. (Right) Schematic signals recorded from a single photoreceptor (top) and from a tangential cell (bottom) during motion of a bar. Although the photoreceptor signal is nondirectional, the signal of the tangential cell is strongly directional.

\section{NEURAL IMPLEMENTATION OF THE HASSENSTEIN-REICHARDT DETECTOR}

Given the evidence that has been accumulated for Hassenstein-Reichardt detector in the optic lobes of different fly species, the question naturally arises: Which neurons form the Hassenstein-Reichardt detector? To answer this question, one first of all needs to know which neurons exist between the photoreceptors and the lobula plate tangential cells. Here, an almost complete catalog has been worked out: Starting with the work of Cajal and Sanchez (1915), the columnar cell types of the lamina, medulla, lobula, and lobula plate have all been identified and described on the basis of Golgi impregnations in the housefly (Strausfeld 1976) as well as in Drosophila (Fischbach and Dittrich 1989). Each lamina column (or cartridge, as it is usually referred to) contains a set of 12 cell types, connected to the photoreceptors either directly or indirectly (Fig. 3A; Meinertzhagen and O’Neil 1991). These lamina neurons connect the photoreceptors to specific layers of the medulla (Takemura et al. 2008, 2013). In the medulla, a single column houses more than 60 different cell types. They can be roughly grouped into four groups: medulla intrinsic (Mi) neurons connect different layers of the medulla to each other (Fig. 3B), transmedulla (Tm) neurons connect specific layers of the medulla to various layers in the lobula (Fig. 3C), transmedulla Y (TmY) neurons connect specific layers of the medulla to various layers in the lobula and lobula plate (Fig. 3D), and bushy T4 cells connect medulla layer 10 to the four layers of the lobula plate (Fig. 3E). In addition, a similar group of bushy T5 cells connect the posterior layer of the lobula to the four layers of the lobula plate (Fig. 3E). However, the small size of all these neurons prohibited electrophysiological recordings in most cases. Therefore, although a rather complete map of all columnar neurons was at hands for long, the visual response properties of most of them were completely unknown until recently, and so were their contributions to motion computation.
Only recently, the advent of sophisticated neurogenetics methods in Drosophila allowed for elucidating the circuits for elementary motion detection. These techniques are all based on a two-component expression system in which a so-called "driver line" defining the neurons where a certain effector gene is expressed is crossed with another line, the so-called "reporter line,"

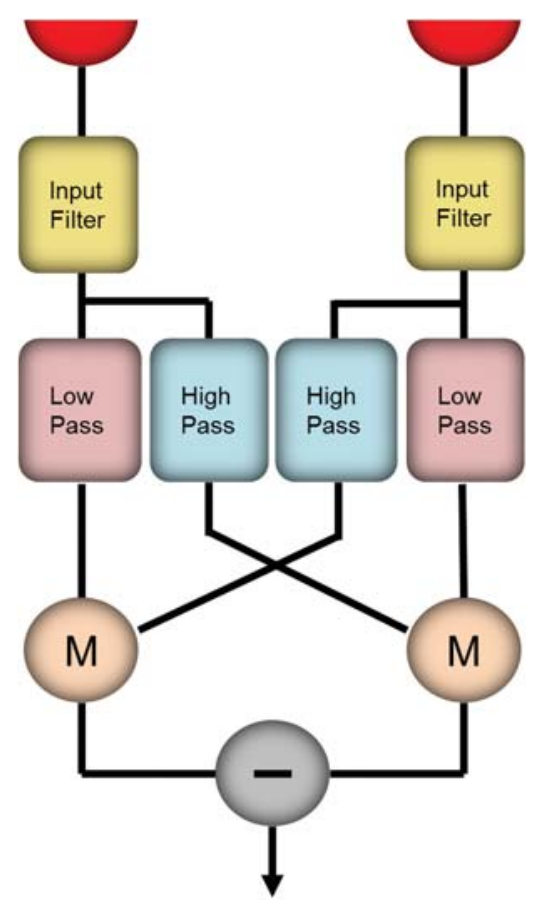

Figure 2. The Reichardt model of elementary motion detection. The model consists of two mirror-symmetrical subunits sharing the same two inputs after passing a filter. Within each subunit, the signal from one input is processed by a temporal low-pass filter and subsequently multiplied $(\mathrm{M})$ with the highpass-filtered signal derived from the neighboring input. The signals from both subunits are subtracted (-), giving rise to a directionally selective output. 
A

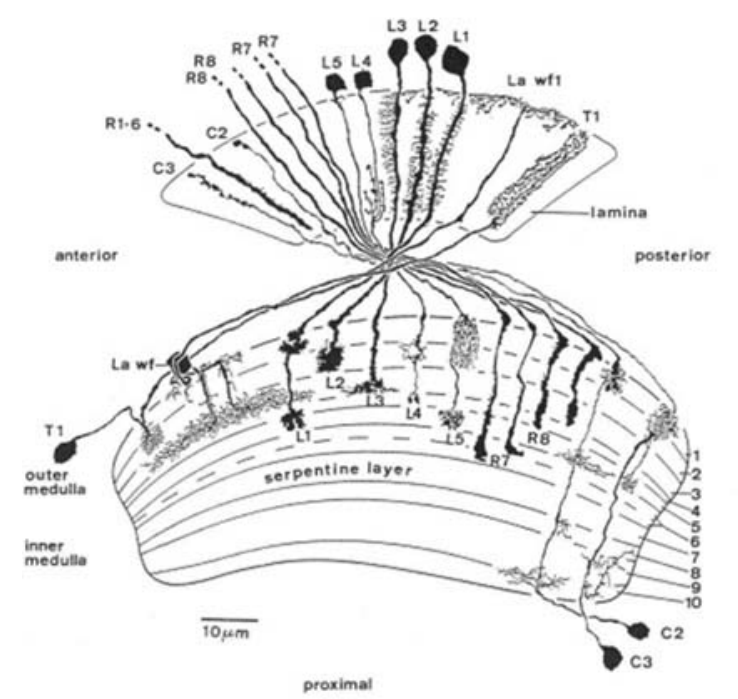

B
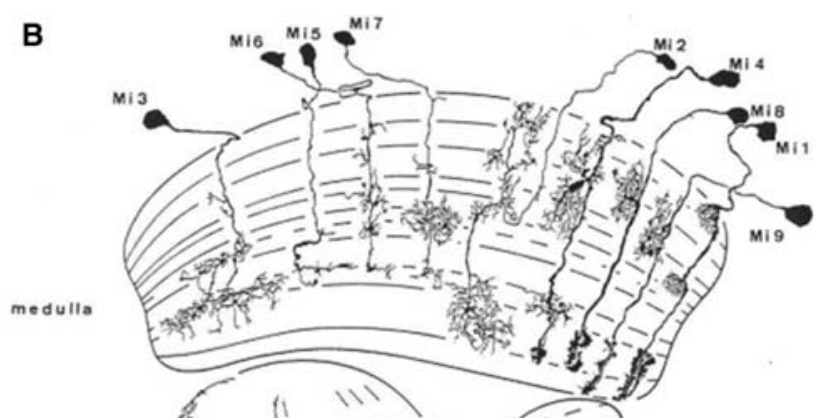

Lt7

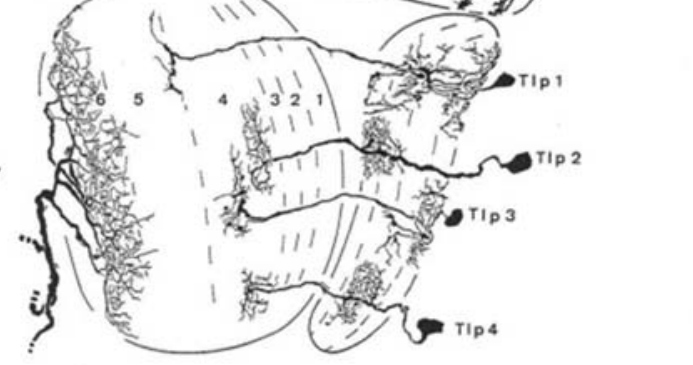

D
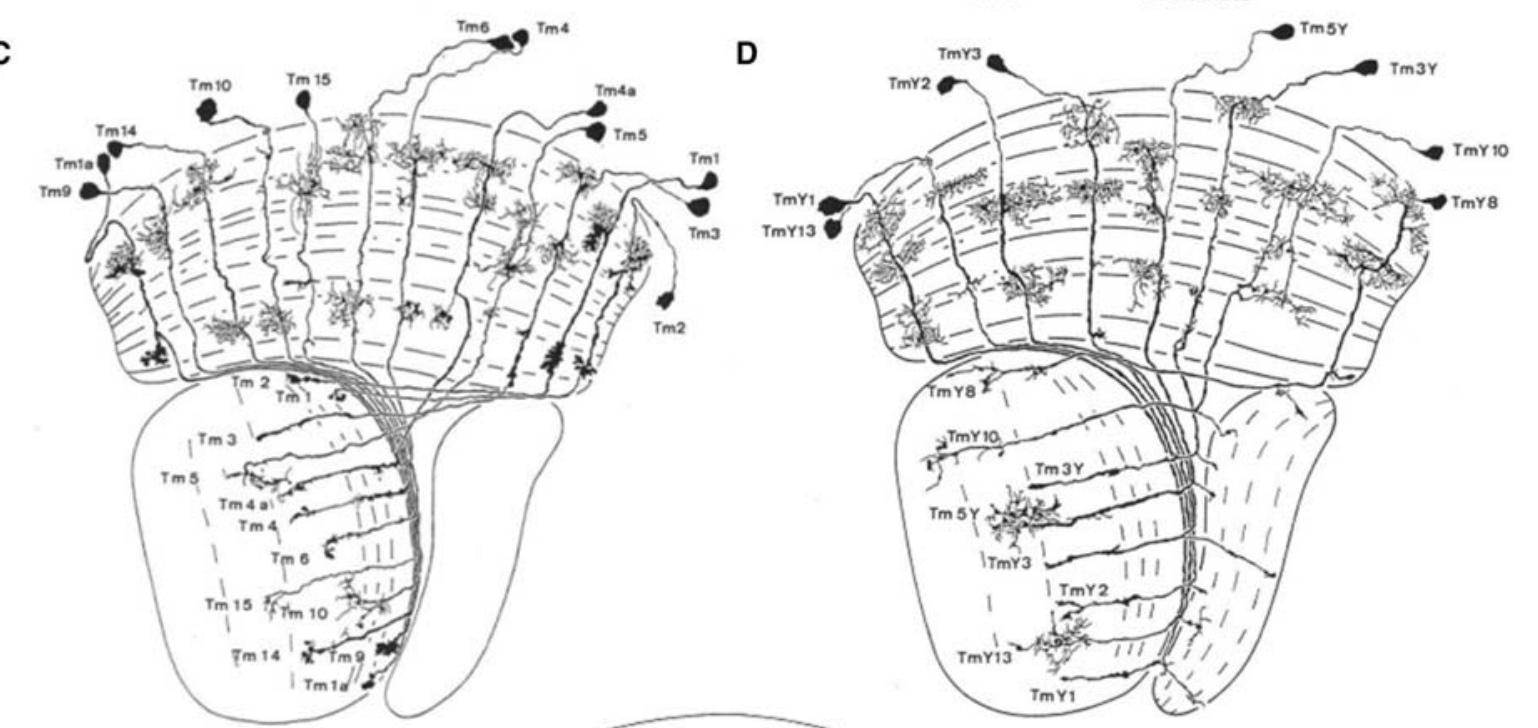

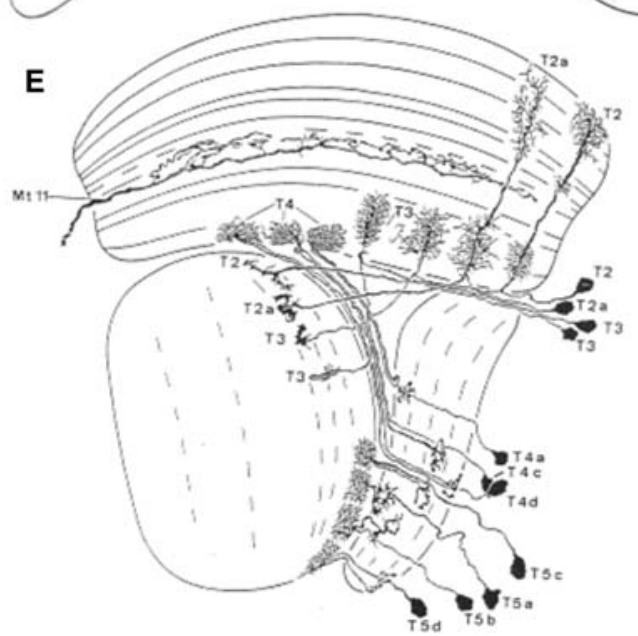

Figure 3. The Golgi catalog of columnar neurons of the Drosophila optic lobe. (Adapted from Fischbach and Dittrich 1989.) 
defining what gene is expressed (Brand and Perrimon 1993). Today, thousands of different driver lines are available, many of which reveal a high degree of specificity for expression in individual cell types of the optic lobe (Pfeiffer et al. 2008; Tuthill et al. 2013). Furthermore, many reporter lines have been developed, allowing for blocking the synaptic output of neurons, activating neurons optogenetically, and recording from neurons via genetically encoded calcium indicators (for review, see Borst 2009; Venken et al. 2011). Applying these techniques to the problem of local motion detection revealed that (a) luminance information from fly photoreceptors R1-R6 is split into two parallel motion circuits, specialized to detect the motion of luminance increments (ON channel) and decrements (OFF channel) separately, (b) lamina neurons L1 and L2 are the primary input neurons to these circuits ( $\mathrm{L} 1 \rightarrow \mathrm{ON}$ channel, L2 $\rightarrow$ OFF channel), and (c) T4 and T5 cells carry their output signals $(\mathrm{ON} \rightarrow \mathrm{T} 4, \mathrm{OFF} \rightarrow \mathrm{T} 5)$ (Joesch et al. 2010, 2013; Eichner et al. 2011; Maisak et al. 2013).

\section{INPUT ELEMENTS}

A single facet of the fly eye comprises two sets of photoreceptors: the peripheral photoreceptors R1-R6 and the central R7,8. Early work on different mutants where either the central or the peripheral ones were defective indicated that motion vision relies primarily on R1-R6, and not on R7 and R8 (Heisenberg and Buchner 1977). The two most prominent target neurons of the peripheral photoreceptors R1-R6 are the large monopolar cells L1 and L2 of the lamina. First evidence for the contribution of L1 and L2 in motion vision was provided by experiments where either behavioral responses (Rister et al. 2007) or electrophysiological recordings from lobula plate tangential cells were used as a readout (Joesch et al. 2010): Blocking both L1 and L2 led to a complete abolishment of the responses to gratings moving along any direction. The individual contributions of L1 and L2 were discovered in flies where either L1 or L2 was blocked, and, instead of gratings, edges of different contrast polarity were moved to probe the responses of lobula plate tangential cells (Joesch et al. 2010). Although control flies responded to moving brightness increments (ON edges) and decrements (OFF edges) with about the same amplitude, flies with lamina neurons L1 blocked completely lost their response to moving ON edges, whereas their response to moving OFF edges was largely intact. The opposite was found for flies with lamina neuron L2 blocked: Here, the response to moving ON edges was roughly as large as the one of control flies, whereas the response to moving OFF edges was severely reduced. Together, these experiments suggest that the photoreceptor input from R1-R6 is split into parallel channels depending on the contrast polarity of the incoming signal: Although lamina neurons L1 specifically transmit information about brightness increments to downstream motion circuits, lamina neurons L2 only allow information about brightness decrements to be passed onto further motion processing units. Technically, such signal processing is referred to as "halfwave rectification." Using a genetically encoded calcium indicator, Reiff et al. (2010) indeed showed that in the OFF pathway, such half-wave rectification starts already in the axon terminal of L2 neurons in layer 2 of the medulla.

\section{TWO PARALLEL MOTION PATHWAYS}

The findings about the specific contribution of L1 and L2 to motion processing of brightness increments and decrements immediately suggests that in Drosophila, motion is detected in several separate circuits. Theoretically, there could be four such channels comprising all possible combinations between $\mathrm{ON}$ and OFF signals. However, apparent motion experiments in blow flies indicated that only two such channels exist, one for the interaction of ON signals and one for the interaction of OFF signals between neighboring image points (Riehle and Franceschini 1984). Recordings from lobula plate tangential cells in Drosophila arrived at the same conclusion: Only sequences of light pulses of the same contrast polarity $(\mathrm{ON}-\mathrm{ON}$ and $\mathrm{OFF}-\mathrm{OFF})$ elicited significant responses, whereas light pulses of differing contrast polarity (ON-OFF and OFF-ON) failed to evoke any responses in lobula plate tangential cells (Eichner et al. 2011). Interestingly, using brightness steps instead of brightness pulses led to different results: Although again, $\mathrm{ON}-\mathrm{ON}$ and $\mathrm{OFF}-\mathrm{OFF}$ sequences along the preferred direction of the cell led to positive responses, ON-OFF and $\mathrm{OFF}-\mathrm{ON}$ sequences elicited negative responses (Egelhaaf and Borst 1992; Eichner et al. 2011). Although this so-called "reverse phi" phenomenon (Anstis and Rogers 1975) was usually taken as evidence for an interaction between $\mathrm{ON}$ and OFF stimuli, as in the original Hassenstein-Reichardt detector, careful simulations of such circuits as well as experiments with flies with either lamina neurons L1 or L2 blocked revealed that such an inversion of the response is not necessarily indicative of an interaction between $\mathrm{ON}$ and OFF channels. Rather, it can be explained by the residual sustained response component of the lamina neurons taking into account the contribution of motion detectors at the edge of the stimulated areas in the visual field of the fly (Eichner et al. 2011; Joesch et al. 2013).

In summary, the Hassenstein-Reichardt detector is implemented in the visual system of the fly in two parallel circuits, one ON channel and one OFF channel (Fig. 4). What could be the advantage of such a doubling of wiring expenditure? With just a single motion detector dealing with brightness going positive as well as negative, a multiplicative interaction-according to the sign rule of multiplication-would imply the output being positive when both input signals go positive as well as when both go negative. Such a processing rule seems hard to implement biophysically and indeed is unheard of in cellular neuroscience. If, however, the input signals are split according to their polarity with the negative ones being sign-invert- 


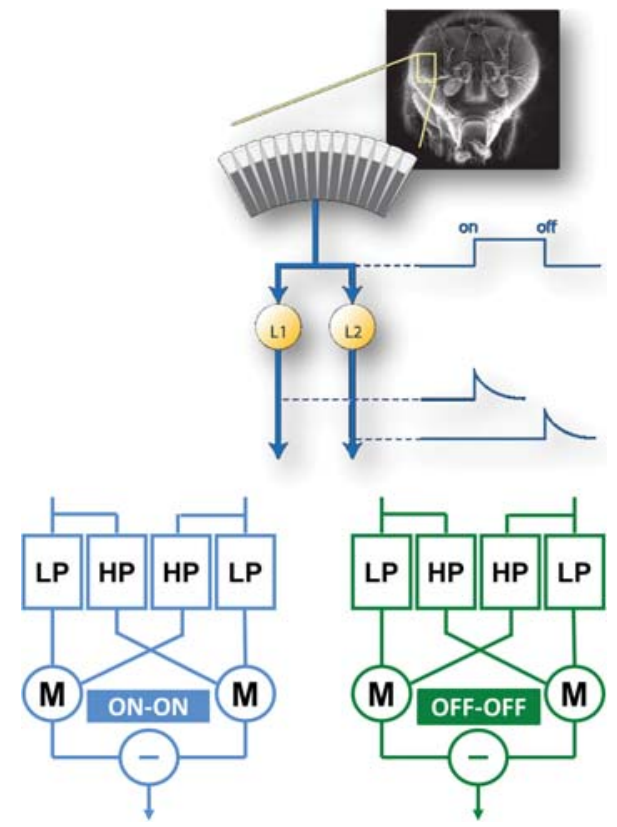

Figure 4. Input organization and general layout of the Reichardt detector as implemented in the Drosophila nervous system. At the level of the lamina, the photoreceptor input is split and halfwave rectified into an ON (L1) and an OFF (L2) signal. Both signals feed into separate motion detection circuits.

ed, subsequent circuits only deal with positive input signals reducing the problem of multiplication to a supralinear input-output characteristic as can be implemented by, for example, a voltage-gated ion channel. Interestingly, analog electronics faced the same problem of multiplying positive and negative signals, and the solution in these days was what is called a "four-quadrant multiplier." There, the input signals, before multiplication, were halfwave rectified, split into parallel ON and OFF channels carrying positive signals only, and subsequently multiplied in four separate multipliers. Their output signals were then added with the appropriate sign (Hassenstein and Reichardt 1956). This looks similar to what we find in the fly, except that the fly seems to discard two of the four units, reducing a true multiplication to a "two-quadrant multiplier." In the context of motion detection, however, this does not have any functional consequences: Because motion of rigid objects gives rise to spatial correlations between time-delayed signals at subsequent image pixels, an $\mathrm{ON}$ event at one location will always correlate with an $\mathrm{ON}$ event at a later point in time at a neighboring location, and the same holds true for OFF events. Consequently, a comparison of a four- and a two-quadrant detector reveals no significant differences in response to realistic visual motion (Eichner et al. 2011).

\section{LOCAL DIRECTIONALLY SELECTIVE NEURONS}

Having identified lamina neurons L1 and L2 as the decisive input elements to two parallel motion detector circuits allowed anatomy to guide the next steps. Indeed, two parallel processing streams had previously been postulated in the fly visual system (Bausenwein and Fischbach 1992; Bausenwein et al. 1992). These studies indicated that an L1 pathway should indirectly lead to T4 cells and an L2 pathway to T5 cells, with both T4 and T5 cells projecting into the lobula plate. Given that four different subtypes of T4 and T5 cells exist terminating in four different layers of the lobula plate (Fischbach and Dittrich 1989), and deoxyglucose labeling showed activity in one of the four layers according to the direction of the stimulus (Buchner et al. 1984), T4 and T5 cells were prime candidates for local elementary motion detectors. Their small size, however, prohibited electrophysiological recordings and let their visual response properties be unknown for long. A recent study (Maisak et al. 2013) circumvented this problem by using driver lines specific for T4 and T5 cells and combining them with a genetically encoded calcium indicator (Akerboom et al. 2012). Using two-photon calcium imaging and stimulating the flies with grating motion in four cardinal directions (front-to-back, back-to-front, upward, downward), Maisak et al. recorded directionally selective activity from T4 and T5 cells in each one of the four lobula plate layers depending on the direction in which the grating was moving (Fig. 5). To assess the particular contribution of T4 and T5 cells to the signals observed in the above experiments, driver lines specific for either T4 or T5 cells were used. Applying the same stimulus protocol as described before, identical results were obtained for both the T4- and the T5-specific driver line. Further experiments revealed similar response properties for T4 and T5 cells with respect to their orientation and velocity tuning (Maisak et al. 2013). If, however, instead of gratings, moving edges with either positive or negative contrast polarity were used as visual stimuli, T4 cells were found to strongly and selectively respond to moving $\mathrm{ON}$ edges, with little or no responses to moving OFF edges, whereas T5 cells selectively responded to moving OFF edges and mostly failed to respond to moving ON edges.

To investigate the specific contributions of T4 and T5 cells to postsynaptic lobula plate cells and visually driven behavior, T4 and T5 cells were genetically blocked and flies subsequently tested. Blocking both T4 and T5 cells led to a complete loss of the motion response in lobula plate tangential cells (Schnell et al. 2012) and of the optomotor response of tethered walking flies (Bahl et al. 2013). Blocking T4 cells specifically led to selective loss of the responses to moving $\mathrm{ON}$ edges, in the electrical signal of tangential cells as well as in optomotor behavior. Conversely, blocking T5 cells led to a loss of the responses to moving OFF edges, again both in the electrical signal of tangential cells as well as in optomotor behavior. In summary, the selective defects of T4 block flies for ON edges and of T5 block flies for OFF edges not only corroborate the above findings about the selective preference of T4 and T5 cells for different contrast polarities, but also show that the signals of T4 and T5 cells are indeed the major, if not exclusive, inputs to downstream circuits and motion-driven behaviors. 
A

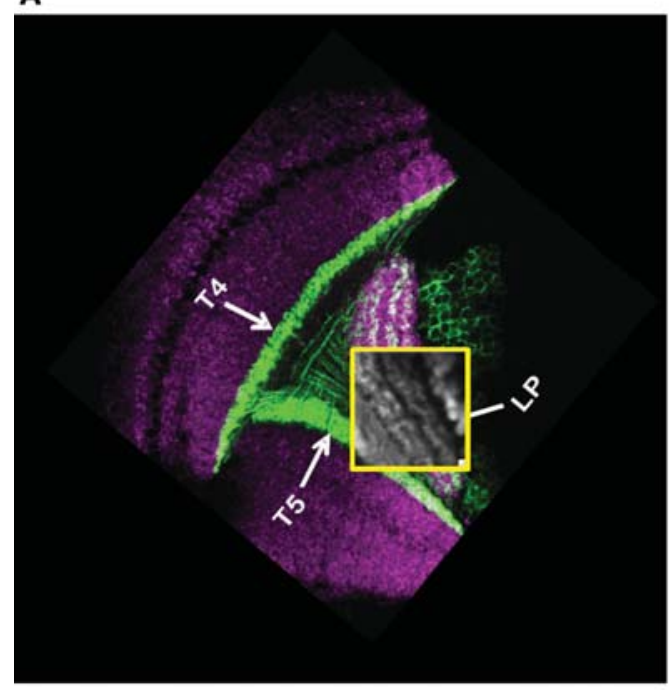

C

T4 Cells

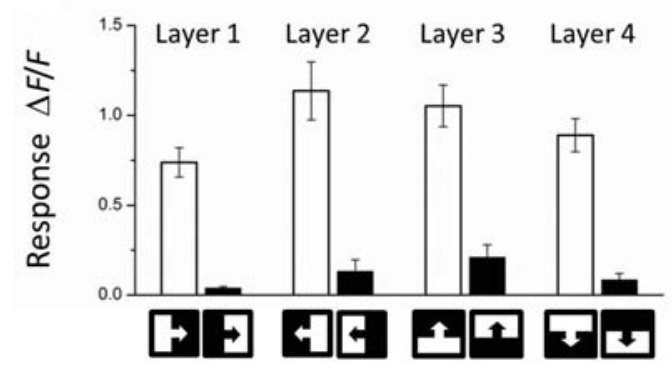

B

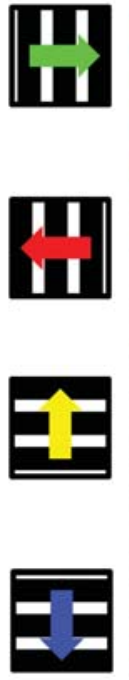

D

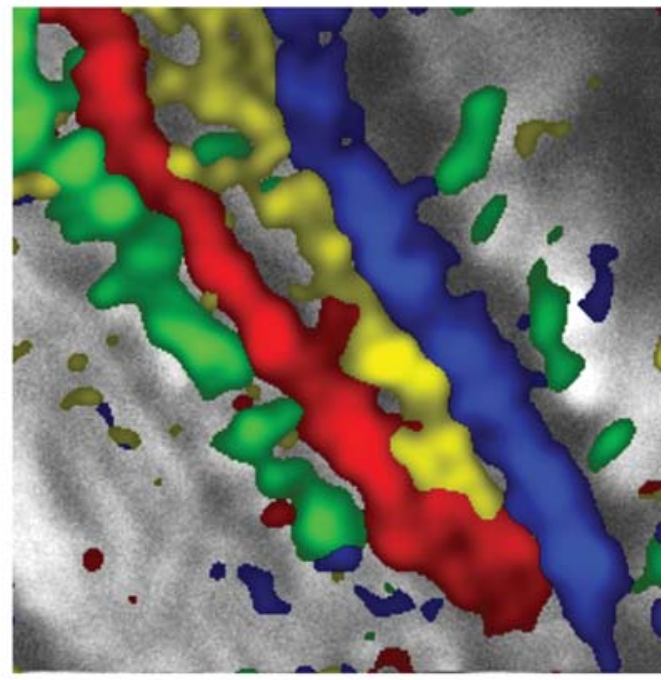

T5 Cells

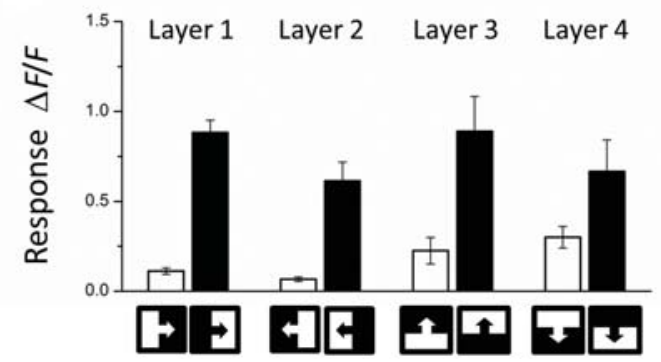

Figure 5. T4 and T5 cells represent the elementary motion detector outputs. $(A)$ Confocal image of a driver line giving rise to expression in both T4 and T5 cells, shown as a horizontal cross section. (Modified from Schnell et al. 2012.) Neurons are marked in green (Kir2.1-EGFP), revealing clear labeling (in green) in the medulla (T4 cell dendrites), in the lobula (T5 cell dendrites), and in four distinct layers of the lobula plate, representing the terminal arborizations of the four subpopulations of both T4 and T5 cells. The inset is from a two-photon microscope and contains the area shown enlarged to the right. $(B)$ Two-photon calcium imaging in the lobula plate reveals directionally selective signals. Following stimulation with grating motion along four cardinal directions, activity is confined to mostly one of the four layers. A particular color has been assigned to each pixel depending on the stimulus direction during which it responded most strongly. (Modified from Maisak et al. 2013.) (C,D) Responses of T4 $(C)$ and T5 (D) cells to ON (in white) and OFF (in black) edges moving along all four cardinal directions. Although T4 cells respond most strongly to moving ON edges, T5 cells almost exclusively respond to moving OFF edges. (Adapted from Maisak et al. 2013.)

\section{IMPLEMENTING MOTION OPPONENCY}

The final processing step of the Hassenstein-Reichardt detector consists of subtracting the signals of motionsensitive units with opposite preferred direction. This can readily account for the depolarization of lobula plate tangential cells during preferred direction motion, and their hyperpolarization during null direction motion. But what might be the cellular basis of this subtraction stage? In both blow flies and fruit flies, evidence exists that the subtraction is realized by a synaptic push-pull organization with local motion detectors of opposite preferred direction providing excitatory and inhibitory input onto the dendrites of lobula plate tangential cells (Borst and Egelhaaf 1990; Borst et al. 1995; Joesch et al. 2008). However, at present it is not known whether and how individual T4 and T5 cells can provide, at the same time, excitation to one and inhibition to the adjacent lobula plate layer. One possibility could be that there exists a separate set of local, inhibitory neurons, like inhibitory twins of the T4/T5 cells. This, however, seems unlikely because blocking of T4 and T5 cells abolishes both the preferred and the null direction response of lobula plate tangential cells in Drosophila (Schnell et al. 2012). As an alternative explanation, a recent study suggests that inhibition is transferred from excitatory T4/T5 signals within one layer of the lobula plate to the adjacent one via local inhibitory interneurons: When T4/T5 cells are optogenetically activated, a fast EPSP (excitatory postsynaptic potential) is recorded in tangential cells, followed by a delayed IPSP (inhibitory postsynaptic potential) (Mauss et al. 2014). Current experiments aim to identify such local inhibitory interneurons and to test whether they indeed provide the inhibition to tangential cells during null direction motion. 


\section{CONCLUSION AND OUTLOOK}

Local motion detection in Drosophila has long been shown to follow the predictions of the HassensteinReichardt detector. However, only the last few years have witnessed a major breakthrough in our understanding of its neural implementation. Genetically targeting individual cell types led to the following picture (Fig. 6): Starting with L1 and L2, the visual input is split into separate ON and OFF pathways, and motion along all four cardinal directions is computed separately within each pathway. The output signals of these eight different motion-detectors are then sorted such that ON (T4) and OFF (T5) motion detectors with the same directional tuning converge in the same layer of the lobula plate, jointly providing the input to downstream circuits and motion-driven behaviors. These findings are in striking similarity to motion processing in the mammalian retina, where the photoreceptor output is split into $\mathrm{ON}$ and $\mathrm{OFF}$ pathways as well, and ON-OFF direction-selective ganglion cells are found in four variants with each group

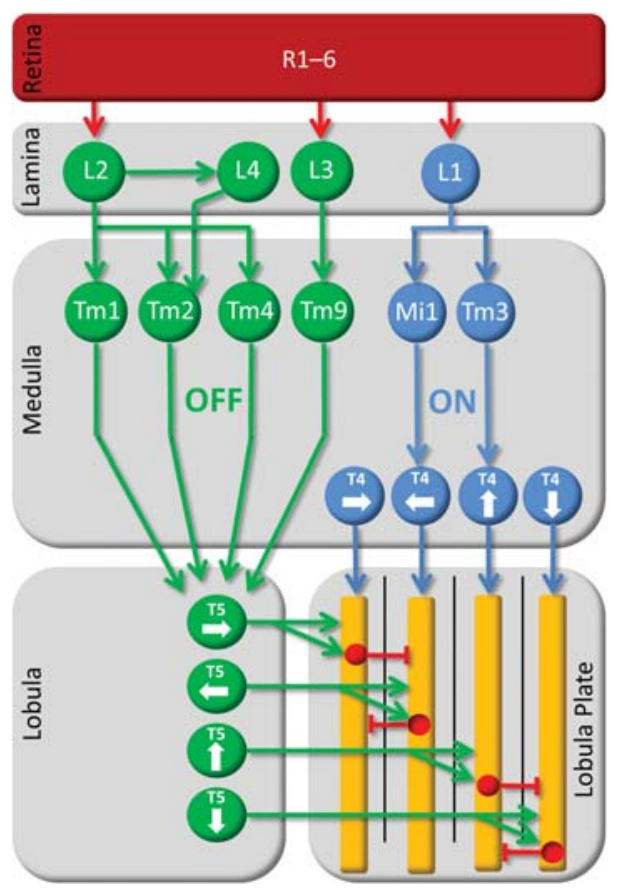

Figure 6. Circuit diagram of the neurons involved in the fly elementary motion detection. Visual input from photoreceptors R1-6 is split into parallel pathways at the level of the lamina. The ON pathway (to the right) is shown to involve lamina neuron L1 and two postsynaptic cells, Mi1 and Tm3, in the medulla. These cells contact the dendrites of T4 cells. The OFF pathway (to the left) involves more neurons. Here lamina cells L2 and L4 synapse onto medulla neurons Tm1, Tm2, and Tm4. In addition, lamina cell L3 synapses onto Tm9 (for involvement of L3, see Silies et al. 2013). All four medulla neurons contact the dendrites of T5 cells. Directionally selective signals are carried via $\mathrm{T} 4$ and T5 cells to the four layers of the lobula plate where T4 and $\mathrm{T} 5$ cells with the same preferred direction converge again on the dendrites of the tangential cells (in yellow). Inhibition is conveyed via hypothetical, local interneurons from one layer to the adjacent one (in red). responding preferentially to one of the cardinal directions (for review, see Borst and Euler 2011).

As an immediate hypothesis derived from the above results, the dendrites of T4 and T5 cells could be the place where the signals from neighboring facets converge, giving rise to $\mathrm{T} 4$ and $\mathrm{T} 5$ cell direction selectivity. Using large-scale serial sectioning transmission electron microscopy and computer-aided reconstruction, Takemura et al. (2013) found two neurons, Mi1 and Tm3, to connect the output terminals of $\mathrm{L} 1$ neurons to the dendrites of T4 cells. In a similar way, four different cells were found to convey the signals from L2 and L3 cells to the dendrites of $\mathrm{T} 5$ cells (i.e., $\mathrm{Tm} 1, \mathrm{Tm} 2, \mathrm{Tm} 4$, and $\mathrm{Tm} 9$ [Shinomiya et al. 2014]). Some of these neurons have meanwhile been characterized physiologically (Behnia et al. 2014; Meier et al. 2014; Strother et al. 2014) confirming their selectivity for either brightness increases or decreases, depending on whether they participate in the ON or the OFF pathway. In line with the above hypothesis, none of these cells showed any sign of direction selectivity. Thus, the major cellular components have been identified and physiologically characterized, and their connectivity established. Nevertheless, we do not know yet how the circuit works. In this context, a recent study made an interesting observation (Behnia et al. 2014): As revealed by whole-cell patch recording from Mi1, Tm1, Tm2, and Tm3 neurons, the dynamics of these four cells show an overall low-pass characteristic with slight differences in the time constants between Mi1 and $\mathrm{Tm} 3$, and $\mathrm{Tm} 1$ and $\mathrm{Tm} 2$, respectively, of $18 \mathrm{msec}$ on average. The authors propose that Mi1 and Tm3 could represent the delayed and nondelayed input channel, respectively, to $\mathrm{T} 4$ cells, whereas $\mathrm{Tm} 1$ and $\mathrm{Tm} 2$ play analogous roles for T5 cells (Behnia et al. 2014). With the measured differences of the time constants, however, the model reproduces a temporal tuning curve consistent with experimental data from $\mathrm{T} 4$ and $\mathrm{T} 5$ cells (Maisak et al. 2013) only after subtraction of mirrorsymmetrical subunits, a process which is thought to be implemented only on postsynaptic tangential cells (Mauss et al. 2014). Furthermore, T5 cells receive input not just from $\mathrm{Tm} 1$ and $\mathrm{Tm} 2$ cells but from two additional types of interneurons. Hence, for these cells, no immediate correspondence to a simple motion-detection scheme exists. As an alternative, the delay might be implemented in the dendritic membrane receptors of T4 and T5 cells: As shown by RNA profiling, T4 and T5 cells express both nicotinic and muscarinic acetylcholine receptors, which could mediate a fast ionotropic and a slow metabotropic signal (Shinomiya et al. 2014). It is therefore left to future studies to determine which cell corresponds to which element of the Hassenstein-Reichardt detector, where and how the delay is implemented, and what the biophysical nature of the nonlinear signal interaction is.

\section{REFERENCES}

Akerboom J, Chen TW, Wardill TJ, Tian L, Marvin JS, Mutlu S, Calderón NC, Esposti F, Borghuis BG, Sun XR, et al. 2012. Optimization of a GCaMP calcium indicator for neural activity imaging. J Neurosci 32: 13819-13840. 
Anstis SM, Rogers BJ. 1975. Illusory reversal of visual depth and movement during changes of contrast. Vision Res 15: 957-961.

Bahl A, Ammer G, Schilling T, Borst A. 2013. Object tracking in motion-blind flies. Nat Neurosci 16: 730-738.

Bausenwein B, Fischbach KF. 1992. Activity labeling patterns in the medulla of Drosophila melanogaster caused by motion stimuli. Cell Tissue Res 270: 25-35.

Bausenwein B, Dittrich AP, Fischbach KF. 1992. The optic lobe of Drosophila melanogaster. II. Sorting of retinotopic pathways in the medulla. Cell Tissue Res 267: 17-28.

Behnia R, Clark DA, Carter AG, Clandinin TR, Desplan C. 2014. Processing properties of ON and OFF pathways for Drosophila motion detection. Nature 512: 427-430.

Borst A. 2009. Drosophila's view on insect vision. Curr Biol 19: R36-R47.

Borst A, Bahde S. 1986. What kind of movement detector is triggering the landing response of the housefly? Biol Cybern 55: 59-69.

Borst A, Egelhaaf M. 1989. Principles of visual motion detection. Trends Neurosci 12: 297-306.

Borst A, Egelhaaf M. 1990. Direction selectivity of blowfly motion-sensitive neurons is computed in a two-stage process. Proc Natl Acad Sci 87: 9363-9367.

Borst A, Euler T. 2011. Seeing things in motion: Models, circuits, and mechanisms. Neuron 71: 974-994.

Borst A, Egelhaaf M, Haag J. 1995. Mechanisms of dendritic integration underlying gain control in fly motion-sensitive interneurons. J Comput Neurosci 2: 5-18.

Borst A, Reisenman C, Haag J. 2003. Adaptation of response transients in fly motion vision. II: Model studies. Vision Res 43: $1309-1322$.

Borst A, Flanagin VL, Sompolinsky H. 2005. Adaptation without parameter change: Dynamic gain control in motion detection. Proc Natl Acad Sci 102: 6172-6176.

Brand AH, Perrimon N. 1993. Targeted gene expression as a means of altering cell fates and generating dominant phenotypes. Development 118: 401-415.

Brenner N, Bialek W, de Ruyter van Steveninck R. 2000. Adaptive rescaling maximizes information transmission. Neuron 26: $695-702$.

Buchner E. 1976. Elementary movement detectors in an insect visual system. Biol Cybern 24: 86-101.

Buchner E, Buchner S, Bülthoff I. 1984. Deoxyglucose mapping of nervous activity induced in Drosophila brain by visual movement. J Comp Physiol A 155: 471-483.

Cajal SR, Sanchez D. 1915. Contribución al conocimiento de los centros nerviosos de los insectos. Imprenta de Hijos de Nicholas Moja, Madrid.

Eckert H. 1973. Optomotorische Untersuchungen am visuellen System der Stubenfliege Musca domestica L. Kybernetik 14: $1-23$.

Egelhaaf M, Borst A. 1989. Transient and steady-state response properties of movement detectors. J Opt Soc Am A 6: 116127.

Egelhaaf M, Borst A. 1992. Are there separate on- and off-channels in fly motion vision? Vis Neurosci 8: 151-164.

Eichner H, Joesch M, Schnell B, Reiff DF, Borst A. 2011. Internal structure of the fly elementary motion detector. Neuron 70: $1155-1164$.

Fermi G, Reichardt W. 1963. Optomotorische Reaktionen der Fliege Musca domestica. Kybernetik 2: 15-28.

Fischbach KF, Dittrich APM. 1989. The optic lobe of Drosophila melanogaster. I. A Golgi analysis of wild-type structure. Cell Tissue Res 258: 441-475.

Goetz KG. 1964. Optomotorische Untersuchung des visuellen Systems einiger Augenmutanten der Fruchtfliege Drosophila. Kybernetik 2: 77-92.

Goetz KG. 1965. Die optischen Übertragungseigenschaften der Komplexaugen von Drosophila. Kybernetik 2: 215-221.

Haag J, Denk W, Borst A. 2004. Fly motion vision is based on Reichardt detectors regardless of the signal-to-noise ratio. Proc Natl Acad Sci 101: 16333-16338.
Hassenstein B, Reichardt W. 1956. Systemtheoretische Analyse der Zeit-, Reihenfolgen- und Vorzeichenauswertung bei der Bewegungsperzeption des Rüsselkäfers Chlorophanus. Z Naturforsch 11b: 513-524.

Heisenberg M, Buchner E. 1977. The role of retinula cell types in visual behavior of Drosophila melanogaster. J Comp Physiol A 117: 127-162.

Joesch M, Plett J, Borst A, Reiff DF. 2008. Response properties of motion-sensitive visual interneurons in the lobula plate of Drosophila melanogaster. Curr Biol 18: $368-374$.

Joesch M, Schnell B, Raghu S, Reiff DF, Borst A. 2010. ON and OFF pathways in Drosophila motion vision. Nature 468: 300-304.

Joesch M, Weber F, Eichner H, Borst A. 2013. Functional specialization of parallel motion detection circuits in the fly. $J$ Neurosci 33: 902-905.

Maisak MS, Haag J, Ammer G, Serbe E, Meier M, Leonhardt A, Schilling T, Bahl A, Rubin GM, Nern A, et al. 2013. A directional tuning map of Drosophila elementary motion detectors. Nature 500: 212-216.

Mauss A, Meier M, Serbe E, Borst A. 2014. Optogenetic and pharmacologic dissection of feedforward inhibition in Drosophila motion vision. J Neurosci 34: 2254-2263.

Meier M, Serbe E, Maisak MS, Haag J, Dickson BJ, Borst A. 2014. Neural circuit components of the Drosophila OFF motion vision pathway. Curr Biol 24: 385-392.

Meinertzhagen IA, O’Neil SD. 1991. Synaptic organization of columnar elements in the lamina of the wild type in Drosophila melanogaster. J Comp Neurol 305: 232263.

Pfeiffer BD, Jenett A, Hammonds AS, Ngo TB, Misra S, Murphy C, Scully A, Carlson JW, Wan KH, Laverty TR, et al. 2008. Tools for neuroanatomy and neurogenetics in Drosophila. Proc Natl Acad Sci 105: 9715-9720.

Reichardt W. 1961. Autocorrelation, a principle for the evaluation of sensory information by the central nervous system. In Sensory communication (ed. Rosenblith WA), pp. 303-317. The MIT Press and John Wiley \& Sons, New York.

Reichardt W. 1987. Evaluation of optical motion information by movement detectors. J Comp Physiol A 161: 533547.

Reiff DF, Plett J, Mank M, Griesbeck O, Borst A. 2010. Visualizing retinotopic half-wave rectified input to the motion detection circuitry of Drosophila. Nat Neurosci 13: 973-978.

Reisenman C, Haag J, Borst A. 2003. Adaptation of response transients in fly motion vision. I: Experiments. Vision Res 43: 1291-1307.

Riehle A, Franceschini N. 1984. Motion detection flies: Parametric control over ON-OFF pathways. Exp Brain Res 54: 390-394.

Rister J, Pauls D, Schnell B, Ting CY, Lee CH, Sinakevitch I, Morante J, Strausfeld NJ, Ito K, Heisenberg M. 2007. Dissection of the peripheral motion channel in the visual system of Drosophila melanogaster. Neuron 56: 155170.

Schnell B, Joesch M, Forstner F, Raghu S, Otsuna H, Ito K, Borst A, Reiff DF. 2010. Processing of horizontal optic flow in three visual interneurons of the Drosophila brain. J Neurophysiol 103: $1646-1657$.

Schnell B, Raghu S, Nern A, Borst A. 2012. Columnar cells necessary for motion responses of wide-field visual interneurons in Drosophila. J Comp Physiol A 198: 389-395.

Shinomiya K, Karuppudurai T, Lin T-Y, Lu Z, Lee C-H, Meinertzhagen IA. 2014. Candidate neural substrates of Off-edge motion detection in Drosophila. Curr Biol 24: $1062-1070$.

Silies M, Gohl DM, Fisher YE, Freifeld L, Clark DA, Clandinin TR. 2013. Modular use of peripheral input channels tunes motion-detecting circuitry. Neuron 79: 111-127.

Strausfeld NJ. 1976. Atlas of an insect brain. Springer, Berlin. 


\section{FLY MOTION VISION}

Strother JA, Nern A, Reiser MB. 2014. Direct observation of ON and OFF pathways in the Drosophila visual system. Curr Biol 24: 976-983.

Takemura SY, Lu Z, Meinertzhagen IA. 2008. Synaptic circuits of the Drosophila optic lobe: The input terminals to the medulla. J Comp Neurol 509: 493-513.

Takemura SY, Bharioke A, Zhiyuan L, Nern A, Vitaladevuni S, Rivlin PK, Katz WT, Olbris DJ, Plaza SM, Winston P, et al.
2013. A visual motion detection circuit suggested by Drosophila connectomics. Nature 500: 175-181.

Tuthill JC, Nern A, Holtz SL, Rubin GM, Reiser MB. 2013. Contributions of the 12 neuron classes in the fly lamina to motion vision. Neuron 79: 128-140.

Venken KJT, Simpson JH, Bellen HJ. 2011. Genetic manipulation of genes and cells in the nervous system of the fruit fly. Neuron 72: 202-230. 


\section{$\$_{\text {CSH }}^{\infty}$ Cold Spring Harbor Symposia SYMPOSIA On Quantitative Biology}

\section{Neural Circuits for Motion Vision in the Fly}

Alexander Borst

Cold Spring Harb Symp Quant Biol 2014 79: 131-139 originally published online December 19, 2014

Access the most recent version at doi:10.1101/sqb.2014.79.024695

References This article cites 51 articles, 8 of which can be accessed free at:

http://symposium.cshlp.org/content/79/131.full.html\#ref-list-1

\section{License}

Email Alerting

Receive free email alerts when new articles cite this article - sign up in

Service the box at the top right corner of the article or click here. 